\title{
Departmentalization for Mathematics: Is It Beneficial for the Teacher, Students, and Teacher Candidates?
}

\author{
Melinda S. Eichhorn \\ Gordon College \\ Courtney Lacson \\ Gordon College
}

\begin{abstract}
Studies have shown that both the departmentalized and self-contained models of instruction can help students achieve strong mathematics scores on standardized tests, and school administrators must consider their teachers and students when deciding on an instructional model. However, little research has considered the effect of the instructional model on initial license teacher candidates and school-university partnerships. Drawing from a Massachusetts college's experience with practicum placements for elementary candidates pursing a generalist license (Grades 1-6), implications for teacher preparation programs are explored as more upper elementary classrooms move to a departmentalized model for mathematics.
\end{abstract}

Keywords: classroom format, departmentalization, self-contained, teacher candidates, mathematics, elementary education

\section{Introduction}

Anna has waited all summer to receive her placement for her practicum (student teaching). When the email from the placement coordinator arrives in her inbox, she is pleased to find out that she will be teaching with Ms. Davis in third grade in an urban school. She can't wait to apply all that she has learned to her practicum-methods courses in literacy, math, social studies and science, children's literature, and classroom management. When she arrives on the first day of her practicum, Anna is disheartened to find out that Ms. Davis is part of a pilot program to departmentalize, and she teaches all the third-grade students math and science, while students switch classrooms for English language arts and social studies. Anna will not have the opportunity to practice being a generalist or have a self-contained classroom. She wonders how she will complete her required lesson plans for her social studies methods course this semester if she is observing and teaching math and science all day. How will the departmentalization model impact her practicum? What if Anna believes that she is more interested in teaching English language arts than math and science?

Although the research on departmentalization and student academic achievement is mixed, there are implications beyond the classroom teacher and elementary school students. Studies have shown that both the departmentalized and self-contained models of instruction can help students achieve strong mathematics scores on standardized tests, and school administrators must consider their teachers and students when deciding on an instructional model. However, what are the implications for teacher candidates? Little research has considered the effect of the instructional model on initial license teacher candidates and school-university partnerships (see Rigelman, 2017, for an exception). In this article, the benefits and drawbacks of departmentalizing are considered through the lens of teacher candidates training to be teachers and their professors. Furthermore, implications for teacher preparation programs are discussed and reflection questions are provided 
for universities and colleges that place teacher candidates in practicum placements that are departmentalized.

\section{Literature Review}

\section{Classroom Format: Departmentalization Model}

A departmentalized model of instruction has one teacher responsible for teaching mathematics to at least two groups of students and does not teach all subjects as would a typical self-contained elementary teacher (Webel, Conner, Sheffel, Tarr, \& Austin, 2017). Due to increased accountability for student achievement in mathematics, many schools have departmentalized or have started a trial of departmentalizing in one or two grades (Baroody, 2017). In a departmentalized format, the teacher has more focused content knowledge and can provide specialized and high-quality instructional support (Baroody, 2017). Some research has shown the departmentalization has increased job satisfaction and reduced stress in teachers (Baroody, 2017). Departmentalization is sometimes referred to as content specialization (Markworth, Brobst, Ohana, \& Parker, 2016).

There are multiple models of departmentalization, including but not limited to (a) taking a blended/integrated or team approach, in which the students at a particular grade level are divided into large teams, each of which is assigned to a group of teachers who work with this team exclusively (the teacher assigned to math also teaches science, and perhaps social studies for their team; Webel et al., 2017) and (b) having a completely separate/grade-level math teacher (the teacher serves as the only mathematics teacher for the entire grade). In some schools, teachers who departmentalize for math or reading are required to obtain some sort of certification to specialize in their content area, whereas in other schools, they are appointed internally in their school or district (Fennell, 2017). Although the requirements for reading specialists are clear in virtually all states, requirements for state certification of the "math specialist" title differ, and some states do not have any required credentials for specialization in math (Rigelman \& Wray, 2017). Currently, 19 states have professional designations for elementary math specialists, and nine additional states are in the process of obtaining state approval for certification/licensure and preparation programs (Elementary Mathematics Specialists and Teacher Leaders Project, 2018). Although Massachusetts guidelines do not include a licensure process for becoming a math specialist, some schools require a teacher to pass a higher level math test for licensure (Massachusetts Test of Education Licensure [MTEL]) to departmentalize (the Elementary, Middle School, or High School Mathematics MTEL).

\section{Classroom Format: General or Self-Contained Model}

When teachers are generalists, they facilitate learning in all subject areas. The most common classroom format for generalizing is a self-contained classroom, in a consistent environment with one teacher (Baroody, 2017). Proponents of self-contained classrooms adhere to a whole-child approach, engaging students in developmentally appropriate methods by developing a close teacher-student relationship that includes the provision of emotional support (Baroody, 2017). Teachers also have flexibility to make connections across subject areas, which promotes student engagement and makes content relevant (Baroody, 2017).

Results of several studies suggest that there is no simple answer as to whether departmentalization "works." Previous research has failed to show a clear impact of departmentalization on student achievement, and this may be because departmentalization in any subject area does not represent a single model, but several different models (Slavin, 1987; Webel et al., 2017). Various models offer teachers and students different kinds of opportunities, which likely influence the degree to which teachers can affect student learning (Webel et al., 2017). 
Wilkins (2010) found that language arts was consistently ranked among the favorite and most enjoyed subjects to teach, in particular for Grades K-2. Mathematics, science, and writing were consistently ranked among the least favorite subjects to teach across all grade levels.

\section{Departmentalization and Setting}

Due to the increased emphasis on student performance on domestic and international assessments, many types of schools (serving students from various socioeconomic backgrounds) are experimenting or consistently using the departmentalized model to try to improve test scores and teacher quality in the mathematics classroom (Jack, 2014). The number of districts and schools adopting the departmentalized model is unclear, due to the various models of departmentalizing and the variability with which they are implemented among schools within the same district. Instances of departmentalization have been researched in both urban (Jack, 2014) and suburban/rural (Moore, 2008; Williams, 2009; Yearwood, 2011) districts.

\section{Teacher Candidates and Licensure Requirements: A Case Study of Massachusetts}

The Every Student Succeeds Act (2015), which took effect in the 2017-18 school year, requires states to establish high academic content standards for their students. Schools must teach all students those standards to help prepare them for college and careers. To ensure that students can reach these high academic standards, educators in Massachusetts need to have the knowledge to support students in mastering prerequisite and advanced standards, including the content in the two grade levels below and above the grade span for the license (Massachusetts Department of Elementary and Secondary Education, 2018). In Massachusetts, the subject matter knowledge guidelines have recently been revised (April 2018) and grounded in the Massachusetts curriculum frameworks so that educators will be more explicitly prepared to enact those standards effectively with students (Massachusetts Department of Elementary and Secondary Education, 2018).

Undergraduate teacher candidates pursuing an education degree and licensure through a higher education institution in Massachusetts must demonstrate subject matter content knowledge, assessed through education licensure tests, as well as pedagogical skill as defined by the "Professional Standards for Teachers," which is assessed by a rubric ("Candidate Assessment of Performance") over multiple observations in a practicum placement. To demonstrate subject matter competency, elementary education majors at colleges in Massachusetts take and pass the MTEL General Curriculum Test, in addition to the Foundations of Reading and Communication and Literacy Tests. The General Curriculum Test has two parts: Multi-subject and Math. According to the MTEL coordinator, the state redeveloped the General Curriculum Test to the current two-part test in 2009 to strengthen the mathematical content knowledge of teachers and to lay the foundation for increasingly demanding levels of math skills and thinking (J. Sohn-White, personal communication, August 9, 2016). According to the MTEL annual pass rate report for 2017-2018 (Massachusetts Teacher Education Licensure, 2019), first-time test takers pass the General Curriculum Math subtest slightly more than $50 \%$ of the time. The director of educator preparation and assessment reported that the Math subtest has one of the weakest pass rates of all MTELs (E. Losee, personal communication, February 8, 2018; Massachusetts Teacher Education Licensure, 2019).

Candidates majoring in elementary education must also complete a practicum, or a field-based experience, supervised by a practitioner and a professor from the college, for their licensure requirement. Teacher candidates pursuing an initial elementary education license in Massachusetts will be able to teach Grades 1-6. Teacher candidates pursuing an initial elementary education license in our state are expected to be generalists (E. Losee, personal communication, February 8, 
2018). Because most departmentalized models involve Grades 3 and higher, we will focus this article on elementary education (through Grade 6), because the early childhood education license in Massachusetts is for Pre-K to Grade 2.

Periodically, the Board of Elementary and Secondary Education approves regulation changes impacting educator licensure, program approval, and license renewal. In 2017, following a statewide regulatory review, licensure changes were made to streamline the regulations and licensure system, close loopholes, clarify certain provisions, and reduce regulatory burden (Massachusetts Office of Educator Licensure, 2017). Because of changes in the licensure regulations and definitions, some teacher candidates may enter their higher education program under the impression that a specific license would be obtained, but this could change before they graduate and complete their program of study. Teacher licenses also vary from state to state in regard to how "elementary" and "middle school" are defined. Currently, Massachusetts is transitioning from a middle school license as Grades 6-8 to an upper license of Grades 5-12 for all content areas except mathematics. If candidates are pursuing an upper license (middle school or secondary), they are expected to departmentalize. For comparison, in Pennsylvania, a middle school license is for Grades 4-8 (Pennsylvania Department of Education, 2019).

\section{Teacher Candidates and School-University Partnerships}

Teacher candidates need experience across subject areas for a generalist elementary education license, Grades 1-6 (E. Losee, February 8, 2018). However, when a school has a departmentalized model, teacher candidates may be placed with a supervising practitioner who teaches only one or two subject areas. In this case, teacher candidates may have multiple supervising practitioners to teach multiple subject areas. They also lack the ability to teach multidisciplinary lessons on a regular basis. This is mostly impacting candidates placed in upper elementary classrooms, Grades 3-5.

Departmentalization may help or hurt our teacher candidates' employability. If teacher candidates apply for departmentalized positions in math and science and have completed their practicum in such a setting, this could be advantageous for them. However, if candidates want to apply for future jobs in a departmentalized setting for English language arts, then a field-experience placement based in a departmentalized math and science classroom would be problematic. If teacher candidates are switching between supervising practitioners, they may lose a sense of routine and structure, as well as consistent feedback across several subjects.

Colleges and universities need to adjust to how schools are changing. If schools are changing their models of instruction for the upper elementary grades, practicum placement coordinators must be aware of these changes by remaining in constant contact with principals about any instructional changes. Because teacher candidates in Massachusetts are receiving an initial elementary education generalist license, they must have generalist experience (E. Losee, February 8, 2018). The director of educator preparation and assessment suggested that colleges and universities should not be using schools that have departmentalized (E. Losee, personal communication, February 8, 2018). However, departmentalized models will lead to fewer potential placements for teacher candidates due to fewer mentor teachers (supervising practitioners) being available.

Some colleges and universities are using placements/schools that have departmentalized, but that have given teacher candidates experience in teaching all content areas. While their supervising practitioner may be in a classroom that is departmentalized for math and science, the teacher candidate may do a partial placement in another classroom to get a balance. Many times, the teacher candidate travels with their "homeroom" group to the other discipline and teaches there (anonymous college director of licensure, placement and supervision, personal communication, April 2, 2018). This model of traveling with the elementary students can work, if two teachers are splitting the 
content and sharing the same 45-50 students. However, when the content is shared among three to four teachers, it becomes more challenging for the teacher candidate and supervising practitioners (as well as the university supervisor) to manage, as reported by a director of field placements and partnerships (Z. Warren, personal communication, June 11, 2018). Overall, colleges and universities use several models, depending on the needs of the elementary schools, but they must ensure that teacher candidates receive experience in all content areas. As more elementary schools departmentalize in the upper elementary grades, especially in Grade 5, there are fewer options for teacher candidate placements and mentor teachers to fulfill the generalist licensure requirements (Z. Warren, personal communication, June 11, 2018).

\section{Implications for Teacher Preparation Programs and School-University Partnerships}

This article presents the strengths and drawbacks for both departmentalization and self-contained classrooms for mathematics. Most of the current research has focused on the impact of these two formats on teachers and students' achievement, leaving out the perspective of teacher candidates and teacher preparation programs at colleges and universities.

At the moment, we recognize that our college is not directly addressing the departmentalization issue in our coursework. Departmentalization has implications for teacher candidates-they can be exploring how they might specialize in the future, even if they must generalize for state licensure at the present. In our math methods class, we can add specific content regarding the pros and cons of departmentalization and discuss ways that elementary education candidates can consider their career trajectory. In advising appointments, we can continue to discuss the impact of the choice of the MTEL to satisfy the math requirement. We can also add a departmentalization debate to our senior seminar, and students can discuss the benefits and drawback of the models and consider how this might impact their job search. Although we are still exploring the implications of departmentalization, we can begin to address the topic in coursework and advising appointments with our teacher candidates.

Also, directors of placement and supervision at colleges and universities can be constantly communicating with principals about changes in their instructional models. Principals and higher education teacher education programs must have open lines of communication to ensure that teacher candidates have generalist experience or opportunities to teach all content areas. In this way, both parties will be working toward a solution, in the best interests of the elementary students, as well as of future educators.

The shift to departmentalization also has implications for the Massachusetts Department of Elementary and Secondary Education. The director of educator preparation and assessment in Massachusetts holds a view of departmentalization that is aligned with research: schools should choose an instructional model for mathematics that makes sense for their students and their school (E. Losee, personal communication, February 8, 2018). Administrators then examine standardized test data in the upper grades to see how students are performing and reflect on what is working and what is not working for their students and staff (E. Losee, personal communication, February 8, 2018). However, the Massachusetts Department of Elementary and Secondary Education appears to be unaware of problems facing teacher preparation programs finding practicum placements for elementary candidates pursing a generalist license (Grades 1-6; E. Losee, personal communication, February 8,2018). Most regulatory changes are driven by demands in the field (by school districts) and changes to the Massachusetts curriculum frameworks (based on Common Core State Standards). 


\section{Conclusion}

Educational entities need to work together to ensure elementary education students attain mathematical proficiency. Although elementary schools use several instructional models for mathematics, including departmentalized and self-contained/generalized models, Massachusetts requires elementary teachers to obtain initial licensure in a generalized model. Elementary teachers licensed in Massachusetts are highly qualified and prepared to teach in any Grade 1-6 classroom. However, potential student teaching/practicum generalist placements in upper elementary grades are shrinking due to the shift to departmentalization. Colleges and universities are using several models to provide a generalist experience to teacher candidates when practicum placements move to the departmentalized model. Schools, state education preparation agencies, state offices of education licensure, and higher education institutions must coordinate their efforts to improve elementary students' mathematics achievement and to prepare future teachers to teach mathematics, as well as all academic subjects. Instructional model changes at the individual school levels can have an impact beyond the elementary students and teachers-future teachers and teacher preparation programs are affected as well.

\section{References}

Baroody, A. E. (2017). Exploring the contribution of classroom formats on teaching effectiveness and achievement in upper elementary classrooms, School Effectiveness and School Improvement, 28, 314-335. doi:10.1080/09243453.2017.1298629

Elementary Mathematics Specialists and Teacher Leaders Project. (2018). Mathematics specialist certification: By state. Westminster, MD: Elementary Mathematics Specialists and Teacher Leaders Project, McDaniel College.

Every Student Succeeds Act, Pub. L. No. 114-95 § 114 Stat. 1177 (2015)

Fennell, F. (2017). We need elementary mathematics specialists now: A historical perspective and next steps. In M. B. McGantha \& N. R. Rigelman (Eds.), Elementary math specialists: Developing, refining, and examining programs that support mathematics teaching and learning (pp. 3-18). Charlotte, NC: Information Age Publishing.

Jack, D. M. (2014). Self-contained versus departmentalized settings in urban elementary schools: An analysis of fifth-grade student mathematics performance (Doctoral dissertation). Retrieved from ProQuest Dissertations Publishing. (3581275)

Markworth, K. A., Brobst, J., Ohana, C., \& Parker, R. (2016). Elementary content specialization: Models, affordances, and constraints. International Journal of STEM Education 3, 16. doi:10.1186/s40594-016-0049-9

Massachusetts Department of Elementary and Secondary Education. (2018). Subject matter knowledge (SMK) guidelines. Retrieved from http://www.doe.mass.edu/edprep/resources/revised-smk-guidelines.pdf

Massachusetts Office of Educator Licensure. (2017). Summary of June 2017 board regulation changes: Educator licensure and preparation program approval (603 CMR 7.00) and educator license renewal (603 CMR 44.00). Retrieved from www.doe.mass.edu/licensure/summaryregulatory-changes-6-17.docx

Massachusetts Teacher Education Licensure. (2019). Annual pass rate report (2017-2018). Retrieved from

https://www.mtel.nesinc.com/Content/TechReport/PDFs/Annual_Pass_Rate_Report_1718.pdf 
Moore, D. W. (2008). Classroom organizational structures as related to student achievement in upper elementary grades in Northeast Tennessee public schools (Doctoral dissertation). East Tennessee State University, Johnson City, TN.

Pennsylvania Department of Education. (2019). Certificates in Pennsylvania: Types and codes. Retrieved from https://www.education.pa.gov/Educators/Certification/PAEducators/Pages/PACerts.aspx

Rigelman, N. R. (2017). Supporting elementary mathematics specialists alongside improving preservice teacher programs. In M. B. McGantha \& N. R. Rigelman (Eds.), Elementary math specialists: Developing, refining, and examining programs that support mathematics teaching and learning (pp. 133-140). Charlotte, NC: Information Age Publishing.

Rigelman, N. R., \& Wray, J. A. (2017). Current state of mathematics specialists state certification and standards. In M. B. McGantha \& N. R. Rigelman (Eds.), Elementary math specialists: Developing, refining, and examining programs that support mathematics teaching and learning (pp. 33-38). Charlotte, NC: Information Age Publishing.

Slavin, R. E. (1987). Grouping for instruction in the elementary school. Educational Psychologist, 22, $109-127$.

Webel, C., Conner, K. A., Sheffel, C., Tarr, J. E., \& Austin, C. (2017). Elementary mathematics specialists in "departmentalized" teaching assignments: Affordances and constraints. Journal of Mathematical Behavior 46, 196-214. doi:10.1016/j.jmathb.2016.12.006

Wilkins, J. L. M. (2010). Elementary school teachers' attitudes toward different subjects. The Teacher Educator, 45, 23-36. doi:10.1080/08878730903386856

Williams, M. W. (2009). Comparison of fifth-grade students' mathematics achievement as evidenced by Georgia's criterion-referenced competency test: Traditional and departmentalized settings (Doctoral dissertation). Liberty University, Lynchburg, VA.

Yearwood, C. (2011). Effects of departmentalized versus traditional settings on fifth graders' math and reading achievement (Doctoral dissertation). Liberty University, Lynchburg, VA.

[Appendix follows] 


\section{Appendix}

\section{Recommendations for Teacher Prep Programs}

As you consider how departmentalization impacts your program, reflect on the following recommendations:

- Discuss the strengths and drawbacks of each classroom instructional model or format in your postsecondary courses.

- Discuss potential paths teacher candidates could take, if they do departmentalize.

- Discuss the impact of the departmentalization model for Grades 3-5 with other teacher preparation programs.

- Inform the State Department of Elementary and Secondary Education of a shrinking placement base for teacher candidates as more and more schools shift to a departmentalized model.

- Explore the option of a two-part departmentalized elementary practicum model—one practicum focused on English language arts/social studies and math/science.

\section{Questions for Reflection}

1. How does departmentalization impact your teacher preparation program?

2. How are you discussing departmentalization with your teacher candidates?

3. How has your state licensure been impacted by school districts shifting to departmentalization?

The Journal of Educational Research and Practice provides a forum for studies and dialogue that allows readers to better develop social change in the field of education and learning. Journal content may focus on educational issues of all ages and in all settings. It also presents peer-reviewed commentaries, book reviews, interviews of prominent individuals, and additional content. The objectives: We publish research and related content that examines current relevant educational issues and processes aimed at presenting readers with knowledge and showing how that knowledge can be used to impact social change in educational or learning environments. Additional content provides an opportunity for scholarly and professional dialogue regarding that content's usefulness in expanding the body of scholarly knowledge and increasing readers' effectiveness as educators. The journal also focuses on facilitating the activities of both researcher-practitioners and practitioner-researchers, providing optimal opportunities for interdisciplinary and collaborative thought through blogging and other communications.

Walden University Publishing: http://www.publishing.waldenu.edu 